\title{
Grafting Carbon Nanotubes on Titanium Surface for Osteoblast Cell Adhesion and Growth
}

\author{
Chang-Jiang Pan ${ }^{1 *}$, Yu-Xiao Dong ${ }^{1}$, Klaus D. Jandt ${ }^{2}$ \\ ${ }^{1}$ Jiangsu Provincial Key Laboratory for Interventional Medical Devices, Huaiyin Institute of Technology, Huai'an, China; ${ }^{2}$ Institute \\ of Materials Science \& Technology, Friedrich-Schiller-University Jena, Jena, Germany. \\ Email: ${ }^{*}$ swjtupcj@163.com
}

Received April 16 ${ }^{\text {th }}, 2012$; revised May 26 ${ }^{\text {th }}, 2012$; accepted June $2^{\text {nd }}, 2012$

\begin{abstract}
Poly(ethylene glycol) (PEG) functionalized single-walled carbon nanotubes (SWCNTs) were covalently grafted on the titanium surface with the aim to provide a new platform for human osteoblast cells (HOCs) attachment. Water contact angle, X-ray photoelectron spectroscopy (XPS), and atomic force microscopy (AFM) results revealed that the PEGfunctionalized SWCNTs were successfully grafted onto titanium surfaces. Cell viability and proliferation showed that the number of viable cells in culture medium increased with the incubation time for both titanium and SWCNT-modified titanium samples, although the SWCNT-modified titanium presented lower cell viability compared to titanium. Cell adhesion experiments suggested that there were no obvious differences in the number of cells adhered on the titanium and PEG-SWCNT-modified titanium, and the number of adhered cells increased with the culture time. To our best knowledge, for the first time the PEG functionalized SWCNTs were grafted on the titanium surface for human osteoblast cell adhesion and growth. The strategy introduced in the present study provides a new idea for the matrix preparation based on CNTs and titanium for the biological application and the new SWCNT-titanium platform has potential applications in implantable materials and bone tissue engineering.
\end{abstract}

Keywords: Carbon Nanotube; Titanium; Osteoblast

\section{Introduction}

Carbon nanotubes (CNTs) hold a great promise in biomedical applications, such as drug delivery agents, biosensors, bone scaffolds materials, and others due to their unique structural, mechanical and electronic properties [1-6]. It has been reported that the modified CNTs can deliver peptides and ribonucleic acid (RNA) into cells without causing cytotoxicity [7-9]. Clearly, the studies that obtained good cell viability present some kind of purification (to remove metallic particles dispersed around CNTs and amorphous carbon) or functionalization of the CNT. Some researchers paid more attention to developing structure-controllable nanocomposites and 3D scaffolds for cell seeding and growth due to the high aspect ratio, stiffness and strength of individual CNTs $[10,11]$. However, the relative biocompatibility of CNTs has caused some controversy. For example, many studies show that CNTs have a cytotoxicity when dispersed in cell culture [12-14]. Some results have shown that both CNTs and functionalized CNTs can enhance cell viability and cell function [11,15-20]. Different conclusions from other studies indicated that both CNTs and fun-

\footnotetext{
*Corresponding author.
}

ctionalized CNTs could not increase cell viability and may even increase cytotoxicity in some cases [21-23]. The main reason for this phenomenon is that the biocompatibility of CNTs depends on many parameters, such as the CNT type (single- or multi-wall) and purity, the length of the tubes, and the type of functionalization as well as the molecular properties of the conjugated groups.

In recent years, CNTs have attracted a great deal of attentions as bone replacement materials because of their biocompatibility with human osteoblast cells. A recent study showed that CNTs coated with poly(carbonate) urethane can provide very high nanosurface roughness which could provide greater hydrophilic surfaces although pure CNT surfaces were extremely hydrophobic [25]. The modified CNTs also can enhance adsorption of fibronectin, which is well known to be critical for mediating the adhesion of anchorage-dependent cells, rendering enhanced cellular functions and tissue growth [24,25]. The osteoblast cell study on poly-L-lactide (PLLA)/MWCNTs (multi-walled CNTs) composites showed that the incorporation of MWCNTs into PLLA can obviously enhance the mitochondrial dehydrogenase (MD) activity [26]. However, no significant differences of cell viability were found for PLLA/MWCNTs composites and con- 
trols. The authors believed that the composites had potential applications in bone tissue engineering. Overall, most current researches showed that the incorporation of CNTs into other biomaterials (polymer or inorganic ceramics) induced a nanostructural surface of the pores of composites which was thought to be beneficial for the cell attachment and proliferation [27].

Titanium has been widely used in orthopedic implants, such as human bone replacement and dental materials due to its excellent mechanical, anticorrosive and biocompatibility characteristics [28]. However, the limited surface bioactivity cannot modulate the interface biological reactions between titanium and living tissue, leading to some problems, such as poor binding ability to bone tissue. Surface modification of titanium holds a great promise to further improve its biocompatibility [29$32]$. In the past decades, many extracellular matrix (ECM) proteins were introduced onto the titanium surface to provide growth microenvironments of osteoblast cells [33-37], resulting in improved biocompatibility. Even so, so far the real bonding to bone has not been achieved after implantation in the early ( $<6$ months) post-implantation period [38].

A recent report demonstrated that the CNTs coatings on titanium surface fabricated by electrodeposition have excellent biocompatibility and can be used for surface treatment as a binder for cell-adhesive protein adsorption on the Ti surface [39]. Compared with the titanium without CNTs, the parallel MWCNTs on titanium surface could enhance osteoblast functions, alkaline phosphatase activity and calcium deposition [40]. One aspect that is characteristic of these CNTs on titanium surface is that the CNTs are physically adsorbed to the substrate. It is, however, desirable to covalently bind CNTs to the substrate. Functionalization of CNTs and titanium is necessary because both lack chemically reactive groups. Polyethylene glycol (PEG) has a low toxicity and is widely used in biomaterials. Functionalized CNTs with PEG could not only decrease the potential toxicity of CNTs but also provide the reactive groups on the surface of CNTs.

In the present study, it was hypothesized that grafting CNTs on titanium surface can enhance the biocompa- tibility, i.e. cell adhesion and proliferation, of titanium substrate. The aim of this study was to test if the grafted CNTs on titanium surface can affect the biocompatibility of substrate. To this end, the titanium surface was functionalized to introduce isocyanate groups which can react with hydroxides on PEG-functionalized CNTs, resulting in covalently binding CNTs to titanium surface. This new substrate was used to provide the platform for human osteoblast cell attachment and growth. To the best of our knowledge, it is the first time to investigate the osteoblast cells behavior on the PEG functionalized SWCNTs scaffold. The present study could contribute toward the understanding of interactions between PEGfunctionalized SWCNTs and osteoblast cells and may have the potential application of CNTs in bone materials.

\section{Materials and Methods}

\subsection{Materials and Reagents}

The titanium samples were obtained by depositing pure titanium on silicon wafer by physical vapor deposition. The thickness of the deposited titanium film was approximately $50 \mathrm{~nm}$. The silicon wafer was cut into $10 \times 10$ $\mathrm{mm}$ slides before use. The PEG functionalized SWCNTs were purchased from Sigma-Aldrich (Shanghai, China) and used as received.

The following reagents were purchased from SigmaAldrich (Shanghai, China) and used as received: $3-(4,5-$ Dimethyl-2-thiazolyl)-2,5-diphenyl-2H-tetrazolium bromide (MTT), aminopropyltrimethoxysilane (APTMS), hexamethylene diisocyanate (HMDI), Dimethyl sulfoxide (DMSO), and tetrahydrofuran (THF). The other reagents used in this study were bought from VWR (Germany) if not specified otherwise.

\subsection{Grafting PEG-Functionalized SWCNTs on Titanium Surface}

The schematic procedure of grafting PEG functionalized SWCNTs on titanium surface is shown in Scheme 1. The titanium samples $(10 \times 10 \mathrm{~mm})$ were firstly sonicated in acetone, ethanol and distilled water for $10 \mathrm{~min}$ in sequence

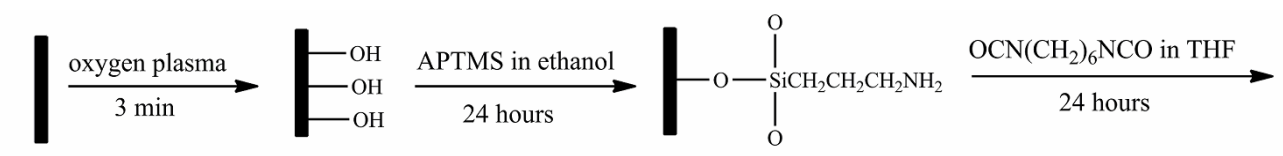

$$
\begin{aligned}
& \text { Titanium } \\
& -\mathrm{O}-\left.\right|_{\mathrm{O}} ^{\mathrm{O}} \mathrm{SiCH}_{2} \mathrm{CH}_{2} \mathrm{CH}_{2} \mathrm{NHCO}\left(\mathrm{CH}_{2}\right)_{6} \mathrm{NCO}
\end{aligned}
$$

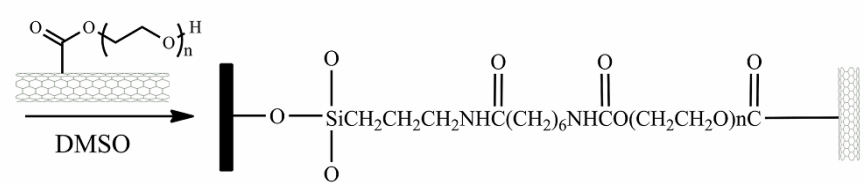

Scheme 1. Schematic diagram of grafting PEG-functionalized SWCNTs on Ti surface. 
and dried by high-pressure compressed air. The cleaned samples were then treated $5 \mathrm{~min}$ by $\mathrm{O}_{2}$ plasma. After rinsing with excess deionized water, the samples were immersed into $10 \mathrm{mM}$ APTMS ethanol solution for selfassembly for 24 hours. The samples were then taken out and sonicated in ethanol and deionized water for $10 \mathrm{~min}$, respectively. The self-assembled samples were immersed into the $100 \mathrm{mM}$ HMDI THF solution. After reacting for 24 hours, the samples were sonicated in THF and dried by air, rendering an isocyanate surface.

The PEG-functionalized SWCNTs were covalently grafted onto titanium surface by incubating the isocyanate surface with $1 \mathrm{mg} / \mathrm{mL}$ DMSO solution of PEGfunctionalized SWCNTs. The substrates were cleaned with water after reacting for 24 hours and dried by highpressure compressed air.

\subsection{Water Contact Angle}

The DSA10 drop shape analysis system was used to measure the water contact angle of all samples using Millipore water. The initial drop volume was $10 \mu \mathrm{L}$ and the dosing rate was set to $10 \mu \mathrm{L} / \mathrm{min}$ for every measurement. The entire measurement consisted of 10 individual measurements, with one-second intervals, over which the average advancing contact angle and standard deviation were calculated. All measurements were performed at room temperature.

\subsection{Surface Chemical Structure Characterization}

The surface chemical structures of original titanium, APTMS, HMDI and SWCNTs-modified titanium surfaces were investigated by XPS. The XPS measurements were done by a Quantum 2000 XPS Apparatus (PHI Co., Chanhassen, MN) with a focused monochromatic Al $\mathrm{K}_{\alpha}$ $\mathrm{X}$-ray source $(1486.6 \mathrm{eV})$ for excitation. The power of the X-ray source was kept at $25.7 \mathrm{~W}$. Multipak software provided by the manufacturer and XPSpeak software were used for curve-fitting and data analysis. Measurements were performed at takeoff angles of $45^{\circ}$.

\subsection{AFM Characterization}

Nanoscope IV multimode AFM (Digital Instruments, Santa Barbara, USA) was used to examine the surface topography of titanium and SWCNTs modified samples using tapping mode at room temperature. Standard $\mathrm{Si}$ cantilever tips from Digital Instruments were used at 1 $2 \mathrm{~Hz}$ of scan rate. The height and phase images were obtained simultaneously and all images were subjected to the first order flatten before further analysis.

\subsection{Cell Culture}

Osteoblasts (CAL-72), derived from human osteosar- coma (ACC439), were purchased from Wuxi BioHermes Co., Ltd of China. These cells were cultured in Dulbecco's modified eagle medium (DMEM, Sigma) containing fetal bovine serum at 37 in a humidified $5 \% \mathrm{CO}_{2}$ atmosphere. Subsequently, the cells were removed by trypsination, washed with DMEM, re-suspended in DMEM, and then used for cell study.

\subsection{MTT Assays}

The MTT assay is colorimetric assay for measuring the activity of enzymes that reduce MTT to formazan dyes which have a maximum light absorbance at $570 \mathrm{~nm}$ after dissolved in DMSO, giving a purple color. It can be used to assess the viability (cell counting) and the proliferation of cells because reduction of MTT can only occur in metabolically active cells and the level of activity is a measure of the viability of the cells. For MTT assay, besides cells deposited on substrates, other cells will remain in culture plate. Therefore, the cells remaining in culture plate could be used to indirectly measure the cells adhered on substrates because the seeded cells are same for each culture pores. In the present study, the purpose of MTT assay was used to investigate the effects of asprepared samples on cell viability in culture medium by measuring the percentage of viable cells cultured with samples to that of reference control culture plate. It also was utilized to examine cell proliferation by measuring the OD optical density of viable cells in culture medium when cultured with samples for different time.

Osteoblast cell viability and proliferation were determined by MTT colorimetric assay. For this purpose, the titanium and SWCNT-titanium samples (each group had four samples) were sterilized with $75 \%$ ethanol for 12 hours and placed in culture plates. $2 \mathrm{~mL}$ of the human osteoblast cells, which were cultured in DMEM supplemented with $10 \%$ fetal bovine serum, were seeded in each well at a concentration of 10,000 cells $/ \mathrm{mL}$. The incubation was performed under $5 \% \mathrm{CO}_{2}$ atmosphere and at $37^{\circ} \mathrm{C}$ for $1,3,7$ days, respectively. After each incubation period, the samples were removed from the respective wells. Subsequently, $10 \mu \mathrm{L}$ of MTT $(5 \mathrm{mg} / \mathrm{mL})$ was added to each well, resulting in a final MTT concentration of $0.5 \mathrm{mg} / \mathrm{mL}$. The cells were incubated for another 4 hours. The produced blue precipitate was dissolved by adding $100 \mu \mathrm{L}$ of DMSO and incubated overnight. After complete solubilization of the dark-blue crystal of MTT formazan, the absorbance of the content of each well was measured at $570 \mathrm{~nm}$ with a 96-well microplate reader on a Power HT spectrophotometer (Bio-Tek Instruments GmbH, Bad Friedrichshall, Germany). The optical density is directly proportional to the number of living cells in culture. The results have been presented in percentage, adopting in $100 \%$ of transmittance for reference cells, i.e. cultures without blank ti- 
tanium or PEG-SWCNTs modified titanium samples.

\subsection{Cell Adhesion}

The cell adhesion of human osteoblast cells on the titanium and SWCNT-titanium surfaces was examined at incubation periods of 1,3 , and 7 days, respectively. After each incubation period, the samples were gently rinsed twice with Phosphate buffered saline (PBS) to remove the non-adhered cells. The attached cells on the substrates were then fixed in $3 \%$ glutaraldehyde in $0.1 \mathrm{M}$ sodium cacodylate buffer for $1 \mathrm{~h}$ and dehydrated in a graded ethanol solution $(25 \%, 50 \%, 75 \%, 90 \%$, and $100 \%)$ series for $10 \mathrm{~min}$. After this, the samples were dried at room temperature for $30 \mathrm{~min}$. Cell adhesion was evaluated by scanning electron microscopy (SEM, Leica S440i, Cambridge, UK) after deposition of a thin gold layer.

\section{Results and Discussion}

\subsection{Surface Modification of Titanium by Grafting CNTs}

Table 1 presents the water contact angle results of titanium surface after each modification step. The water contact angle decreased from $75.8^{\circ} \pm 0.26^{\circ}$ for titanium surface to $66.9^{\circ} \pm 0.97^{\circ}$ for APTMS modified titanium surface because of the introduction of amine groups after self-assembly of APTMS, which indicates that an APTMS layer formed on the titanium surface. The water contact angle further decreased after grafting SWCNTs although the CNT surface is extremely hydrophobic. Two reasons could contribute to this result, one is because the PEG molecules on SWCNTs surface have more hydrophilic activity, and another is because grafting CNTs on titanium surface could produce higher surface roughness at the nanoscale which provides larger hydrophilic surfaces [24]. The water contact angle of HMDI reacted samples was not measured because the isocyanate groups can react with water during measuring contact angle, which leads to inaccurate results.

The surface chemical structure of samples after each modification was investigated by XPS. Typical survey spectra of the blank titanium surface, APTMS-modified, HMDI-modified and SWCNTs-modified surface are shown in Figure 1. The corresponding elemental concentrations of different samples are shown in Table 2. The blank titanium surface showed $\mathrm{Ti}_{2 \mathrm{p}}, \mathrm{O}_{1 \mathrm{~s}}$, as well as $\mathrm{C}_{1 \mathrm{~s}}$ and a weak $\mathrm{N}_{1 \mathrm{~s}}$ core level line, indicating that the normal contamination of samples exposed to air. After deposition of APTMS layer, the relative intensity of the $C_{1 s}$ peak increased concurrently with an occurrence of the strong $\mathrm{Si}_{2 \mathrm{p}}$ and $\mathrm{N}_{1 \mathrm{~s}}$, suggesting successful self-assembly of APTMS on titanium. The relative intensity of the $\mathrm{N}_{1 \mathrm{~s}}$ further increased after reacting with HMDI because the
Table 1. Water contact angle values for the modified samples.

\begin{tabular}{ccc}
\hline Titanium & APTMS-modified & SWCNT-modified \\
\hline $75.8^{\circ} \pm 0.26^{\circ}$ & $66.9^{\circ} \pm 0.97^{\circ}$ & $63.5^{\circ} \pm 1.03^{\circ}$ \\
\hline
\end{tabular}

Table 2. Surface composition of the modified samples by XPS analysis.

\begin{tabular}{cccccc}
\hline \multirow{2}{*}{ Samples } & \multicolumn{5}{c}{ Compositions (at\%) } \\
\cline { 2 - 6 } & $\mathrm{C}_{1 \mathrm{~s}}$ & $\mathrm{~N}_{1 \mathrm{~s}}$ & $\mathrm{O}_{1 \mathrm{~s}}$ & $\mathrm{Si}_{2 \mathrm{p}}$ & $\mathrm{Ti}_{2 \mathrm{p}}$ \\
\hline Titanium & 20.67 & 1.94 & 47.51 & 0.00 & 29.88 \\
APTMS modified & 46.58 & 8.50 & 29.39 & 12.11 & 3.43 \\
HMDI modified & 44.18 & 9.90 & 31.89 & 7.69 & 6.35 \\
SWCNTs modified & 57.01 & 7.68 & 26.62 & 4.11 & 4.58 \\
\hline
\end{tabular}

HMDI contains two nitrogen atoms in its chemical structure. The $\mathrm{N}_{1 \mathrm{~s}}$ density decreased after grafting CNTs because of the high increase of $\mathrm{C}_{1 \mathrm{~s}}$. The decrease of $\mathrm{Si}_{2 \mathrm{p}}$ intensity after each modification step is because the applied molecules cover titanium surface step by step, it also can be used to explain why the intensity of $\mathrm{Ti}_{2 p}$ decreased after each reaction. Figure 2 shows the $C_{1 s}$ Gaussian-Lorenzian curve deconvolution of APTMSand SWCNT-modified samples. The $\mathrm{C}_{1 \mathrm{~s}}$ high resolution spectrum of APTMS-modified titanium sample can be fitted three peaks, which are corresponding to $\mathrm{C}-\mathrm{C}$ (285.2 $\mathrm{eV}), \mathrm{C}-\mathrm{Si}(284.7 \mathrm{eV})$ and $\mathrm{C}-\mathrm{N}(285.6 \mathrm{eV})$, respectively, which is consistent with the chemical structure of APTMS. After grafting the PEG functionalized SWCNTs, in addition to $\mathrm{sp}^{2} \mathrm{C}=\mathrm{C} / \mathrm{sp}^{3} \mathrm{C}-\mathrm{C}(285.2 \mathrm{eV}), \mathrm{C}-\mathrm{N}(285.8$ $\mathrm{eV})$ and $\mathrm{C}-\mathrm{Si}(284.7 \mathrm{eV})$, the occurrence of $\mathrm{C}-\mathrm{O}(286.6$ $\mathrm{eV}), \mathrm{COO}(288.8 \mathrm{eV})$ and $>\mathrm{C}=\mathrm{O}(287 \mathrm{eV})$ indicates that PEG-functionalized SWCNTs were successfully grafted on the titanium surface.

In order to detect the existence of SWCNTs on the titanium surface, AFM was used to characterize the surface topography of modified and control samples. Figure 3 shows the AFM images of titanium and CNT-titanium. It can be found that SWCNTs were distributed on the titanium surface randomly. The nanosurface caused by immobilizing SWCNTs on titanium can provide more hydrophilic activity than titanium, which was confirmed by water contact angle experiments. Taking all these results into consideration, we confirmed that the PEG functionalized SWCNTs were successfully grafted on titanium surface.

\subsection{Cell Viability and Proliferation}

The cell viability and proliferation were examined by MTT assay. The MTT assay is a standard colorimetric assay for measuring the activity of enzymes that reduce MTT to formazan. It can be used to measure the concentration of living cells in culture medium because only 

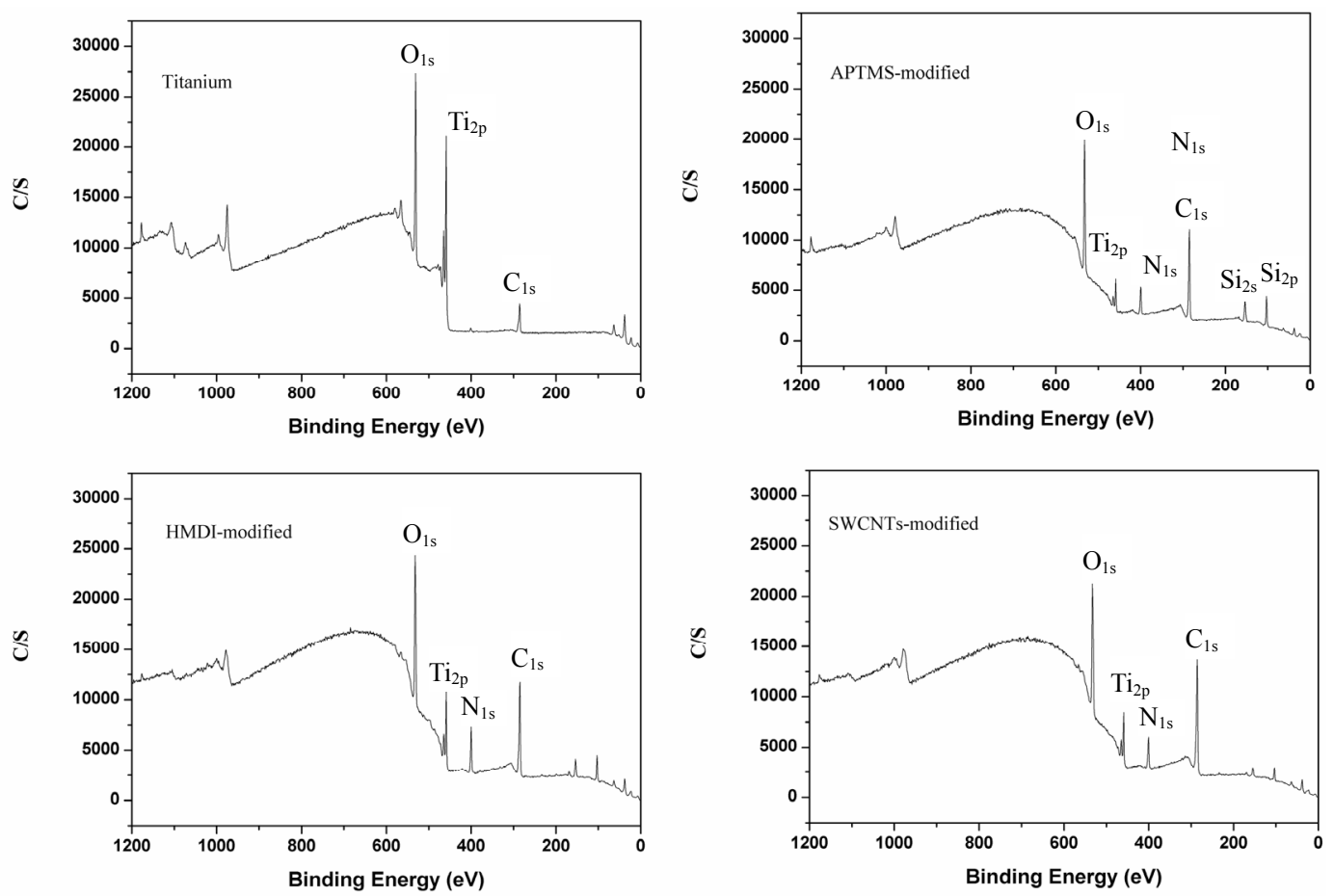

Figure 1. Representative XPS survey spectra of blank Ti surface, APTMS-modified, HMDI and SWCNT-modified Ti surfaces.

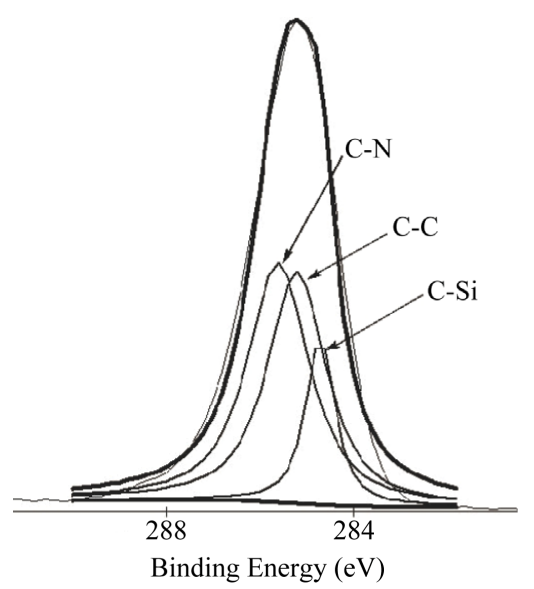

(a)

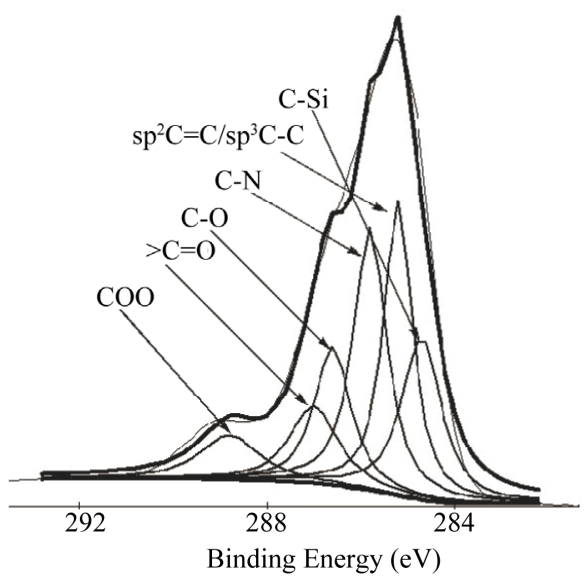

(b)

Figure 2. Gaussian-Lorenzian curve deconvolution of $\mathrm{C}_{1 \mathrm{~s}}$ high resolution spectra of APTMS-modified (a) and SWCNTmodified (b) samples.
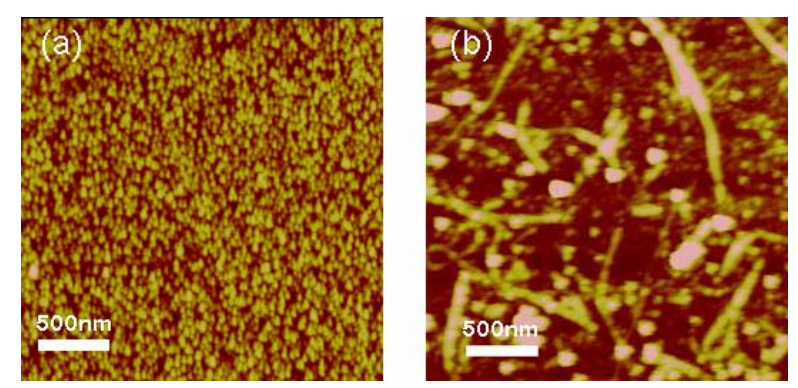

Figure 3. AFM images of Ti (a) and SWCNT-modified Ti (b) surfaces. viable cells can express the mitochondrial dehydrogenase enzyme to cleave the tetrazolium rings of the MTT and form dark blue formazan crystals [37]. Therefore, the MTT results can reveal the cell viability and proliferation.

The cell viability obtained by MTT assays is shown in Figure 4(a). It was expressed as the percentage of viable cells cultured with samples to that of reference plate when cultured for the same time. The cell viability of osteoblast cells incubating on the titanium sample was higher than $95 \%$ after culturing 1 day and the value 
reached to about $100 \%$ after culturing for 3 days. The cell viability decreased significantly after culturing for 7 days, indicating that viable cells in culture medium containing titanium sample was less than that of reference plate, the cell proliferation in culture medium may have been prevented to some degree. For the SWCNTmodified samples, the cell viability was higher than $75 \%$ after culturing for 1 day and increased to $78 \%$ after culturing for 3 days, which means no toxicity after 3 days incubation. However, the same as titanium, the cell viability decreased remarkably after culturing for 7 days to reach 54\%. It suggests that the SWCNTs-modified titanium surface could inhibit cell differentiation to some degree. On the whole, the cell viability of osteoblast cells culturing with titanium and SWCNT-titanium decreased with the increase of culture time. It suggested that, as compared to reference cell (the cells in culture plate without any blank titanium and SWCNT-titanium), both titanium and SWCNT-titanium could cause reduced cell viability in culture medium. So, the osteoblast cells cultured with titanium or SWCNT-titanium showed a relative low proliferation rate as compared with reference osteoblast cells. Even so, it does not mean that cell cannot proliferate when cultured with titanium or SWCNTtitanium. It is concluded that the titanium or SWCNTtitanium may have cytotoxicity when both of substrates were exposed to culture medium containing osteoblast cells. On the other side, more cells attached onto substrates when cultured more time may also contribute to decreased cell viability in culture medium. The increase of adhered cells would result in decrease of viable cells in culture medium.

On the other side, it can be clearly found from Figure 4(a) that the cell viability of titanium is larger than that of SWCNT-titanium in the whole measure time, indicating that the growth rate of osteoblast cells culturing with SWCNT-titanium is lower than that of culturing with titanium. The decrease of cell viability may be related to the nature of the substance itself as well as to its surface state. Grafting CNTs on titanium surface provides nanosurface and more roughness which is very important for cell behavior [42], rendering decreased cell viability. The PEG on the CNTs may be another factor contributing to decreased cell viability.

Figure 4(b) shows the optical densities of osteoblast cells in culture medium interacting with titanium and SWCNT-titanium for 1, 3, 7 days, respectively. It can be found that the optical densities of both titanium and SWCNT-titanium increased with the increase of culture time, suggesting cell proliferation. On the other side, after culturing 3 and 7 days, the optical densities of viable cells were larger than that of the control cells after culturing 1 day, indicating both titanium and SWCNTtitanium have no obvious toxicity to osteoblast cells. The

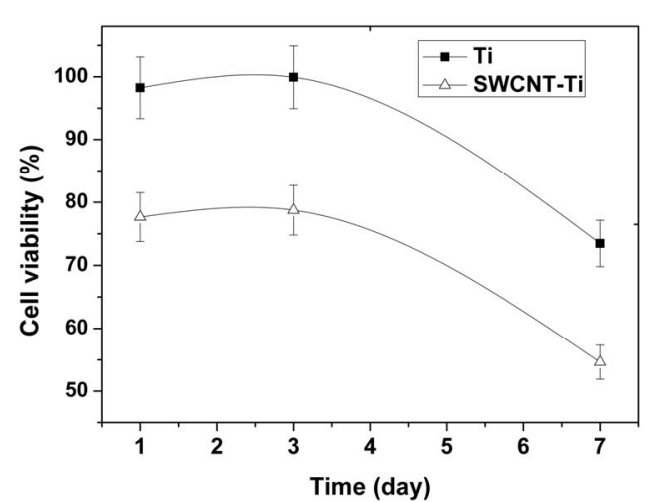

(a)

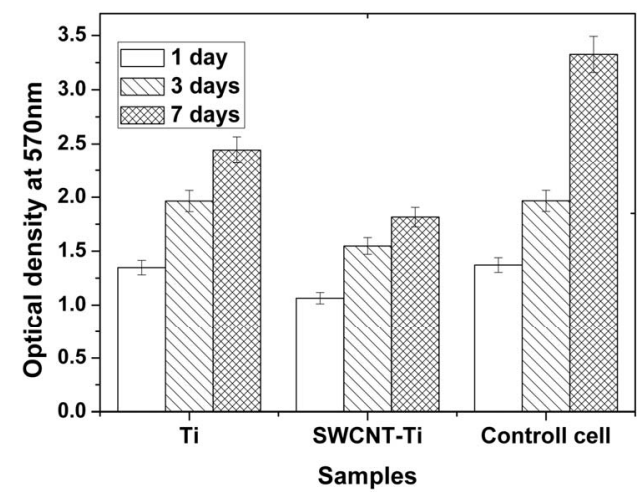

(b)

Figure 4. (a) Human osteoblast cells viability curve measured by MTT assay. The percentage of cell viability is calculated by adopting in $100 \%$ of transmittance for reference cells, i.e. cultures without materials; (b) OD values of osteoblast cells in culture medium when cultured for 1,3 , and 7 days, respectively. The change of $O D$ values represents the cell proliferation of osteoblasts cultured in culture plate.

optical density of osteoblast cells incubated with titanium was larger than that of SWCNT-titanium, suggesting more proliferation. Based on these results, it may be concluded that the PEG functionalized SWCNTs do not induce cytotoxic response and cells can adhere and grow on SWCNT-titanium surface because the cell number increased with the increase of culture time.

From the data shown in Figure 4, it can be seen that the osteoblast cells can proliferate although there was a significant reduction in cell viability when cells were grown on CNT-modified titanium surface. So, the advantage of the present study may provide a new surface treatment method to prepare a novel platform for osteoblast cell adhesion. By altering the functional group (such as carboxyl group) on SWCNT surface and on titanium (such as amine, hydroxyl, etc), new surface treatment route would be developed. On the other side, it can be seen that titanium surface would become more hydrophilic after grafting SWCNT, therefore, the method in this study could be used to improve surface hydrophilicity of titanium and then the modified surfaces may 
be used in other biomaterials field such as blood-contacting biomaterials or non-fouling biomaterials.

\subsection{Cell Adhesion}

Figure 5 shows the typical SEM images of adhered cells on titanium and SWCNT-titanium when culturing for different periods. It can be seen that there was no obvious difference of cell adhesion between titanium and SWCNTtitanium when culturing for different time, indicating that the immobilized CNTs did not prevent cell adhesion and growth as compared with titanium substrate. The analysis of Figure 5 shows that the osteoblast cells adhered on both titanium and SWCNT-titanium spread flat to cover the sample surface after culturing for 1 day. It was suggested that the cell can adhere and spread well on both substrates. After 3 days of culture, the cells still spread well to encounter the neighbor cells to form a cell monolayer. The cells spread with no preferential direction, since they acquire a roughly flat form over the surface.

It is well known that the adhered osteoblast cells on substrate could proliferate to form multilayer cells and the adhered cells will synthesize and secrete type I collagen so that it can mineralize to form bone nodule $[35,36]$. It appears from Figure 5 that after 7 days of culture the first cell layer may covered by many other particle-like substances which may be the proteins secreted by the adhered cells. These secreted proteins could provide extracellular matrix for hydroxyapatite (HA) growth to form bone. Whether these proteins can enhance cell adhesion and growth or HA growth will be confirmed in future work. The magnified SEM images further suggest that many particle-like substances form on the first cell layer. Clearly, it is not osteoblast cells. What are these particles and why the cells produce these particles will be further studied in future work. Also, it appeared that there was a tendency that more particles form on SWCNTs modified titanium substrate. It was suggested that the SWCNTs on titanium surface may enhance the function of adhered osteoblast cells.

The overall observation showed that the PEG-functionalized SWCNTs were not obviously toxic to the osteoblast cells since the number of adhered cells increased significantly with increase of culture time and the adhered cells secreted proteins after culturing for 7 days.

\section{Conclusion}

We demonstrated the grafting of PEG functionalized SWCNTs on titanium and investigated the cell viability, proliferation and adhesion on PEG-SWCNT-titanium substrates. Although osteoblast cells incubating with the titanium sample presented higher cell viability than that of SWCNTs-modified samples, the MTT results showed
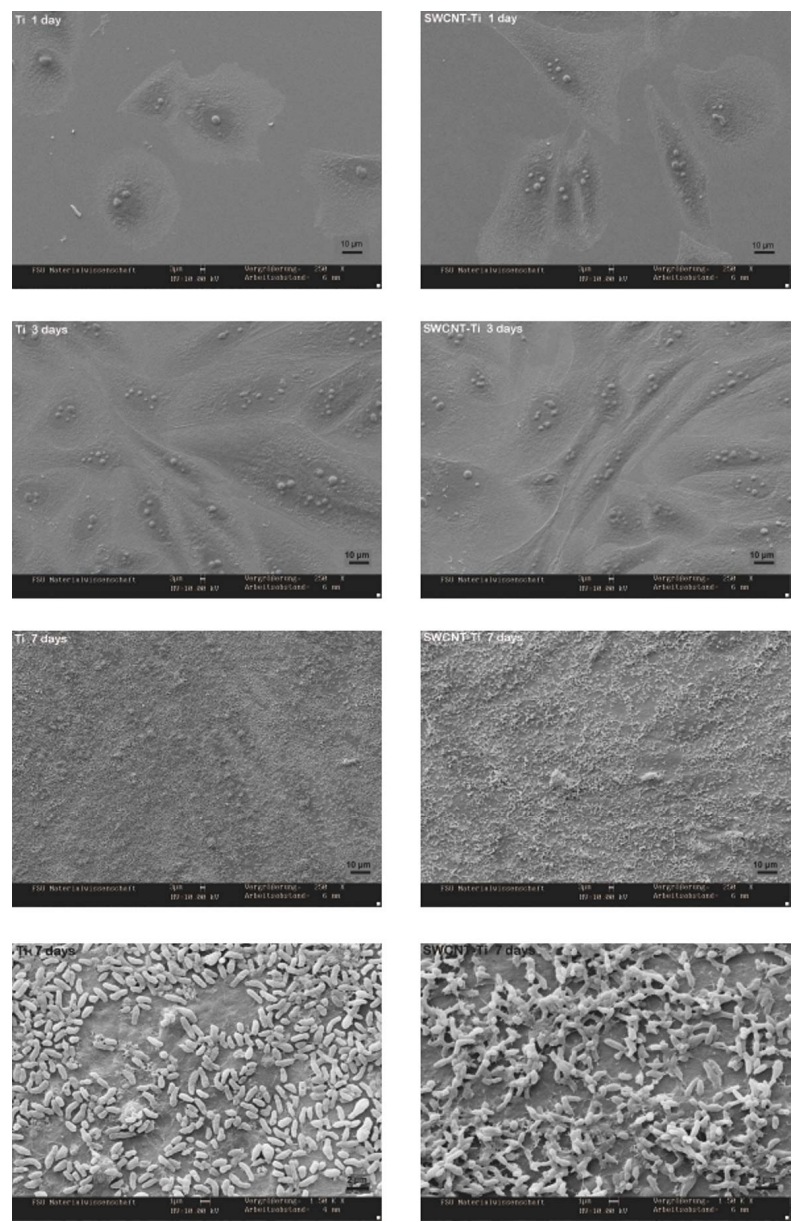

Figure 5. Representative SEM images of adhered cells on titanium and SWCNT-titanium, culturing for 1, 3, 7 days, respectively. The last two images show the larger magnification surface morphology of the Ti and SWCNT-Ti after culturing 7 days.

that the grafted SWCNT had no cell toxicity because the optical density of living cells increased with the increase of culture time. Cell adhesion results suggested that there were no obvious differences between unmodified titanium and SWCNT-titanium. The results of this present study suggested that the SWCNTs grafted on titanium had no cytotoxicity for osteoblast cells, demonstrating its potential as the orthopedic materials. The strategy introduced in the present work provides a new idea for the matrix preparation based on CNTs and titanium for the biological application and the new SWCNT-titanium platform has potential applications in implant materials and bone tissue engineering.

\section{Acknowledgements}

This work is financially support by the Natural Science Fund of China (30900294) and the Scientific Research Foundation for Returned Scholars, Ministry of Education of China (2010-1561). 


\section{REFERENCES}

[1] R. A. Dubin, G. C. Callegari, J. Konh and A. V. Neimark, "Carbon Nanotube Fibers Are Compatible with Mammalian Cells and Neurons," IEEE Transactions on Nanobioscience, Vol. 7, No. 1, 2008, pp. 11-14. doi:10.1109/TNB.2008.2000144

[2] K. D. Jandt, "Evolutions, Revolutions and Trends in Biomaterials Science-A Perspective," Advanced Engineering Materials, Vol. 9, No. 12, 2007, pp. 1035-1050. doi:10.1002/adem.200700284

[3] Y. Liu, D. C. Wu, W. D. Zhang, X. Jiang, C. B. He, T. S. Chung, S. H. Goh and K. W. Leong, "PolyethylenimineGrafted Multiwalled Carbon Nanotubes for Secure Noncovalent Immobilization and Efficient Delivery of DNA," Angewandte Chemie International Edition, Vol. 44, No. 30, 2005, pp. 4782-4785. doi:10.1002/anie.200500042

[4] Z. Liu, K. Chen, C. Davis, S. Sherlock, Q. Cao, X. Chen and H. Dai, "Drug Delivery with Carbon Nanotubes for in Vivo Cancer Treatment," Cancer Research, Vol. 68, 2008, pp. 6652-6660. doi:10.1158/0008-5472.CAN-08-1468

[5] W. Yang, P. Thordarson, J. J. Gooding, S. P. Ringer and F. Braet, "Carbon Nanotubes for Biological and Biomedical Applications," Nanotechnology, Vol. 18, No. 41, 2007, pp. 412001-412012.

doi:10.1088/0957-4484/18/41/412001

[6] M. Kalbacova, M. Kalbac, L. Dunsch and U. Hempel, "Influence of Single-Walled Carbon Nanotube Films on Metabolic Activity and Adherence of Human Osteoblasts," Carbon, Vol. 11, No. 30, 2007, pp. 2266-2272. doi:10.1016/j.carbon.2007.06.025

[7] D. Pantarotto, J. P. Briand, M. Prato and A. Bianco, "Translocation of Bioactive Peptides across Cell Membranes by Carbon Nanotubes," Chemical Communications, Vol. 7, No. 1, 2004, pp. 16-17. doi:10.1039/b311254c

[8] Z. Zhang, X. Yang, Y. Zhang, B. Zeng, S. Wang, T. Zhu, R. B. S. Roden, Y. Chen and R. Yang, "Delivery of Telomerase Reverse Transcriptase Small Interfering RNA in Complex with Positively Charged Single-Walled Carbon Nanotubes Suppresses Tumor Growth," Clinical Cancer Research, Vol. 12, 2006, pp. 4933-4939. doi:10.1158/1078-0432.CCR-05-2831

[9] H. Dumortier, S. Lacotte, G. Pastorin, R. Marega, W. Wu, D. Bonifazi, J. P. Briand, M. Prato, S. Muller and A. Bianco, "Functionalized Carbon Nanotubes Are NonCytotoxic and Preserve the Functionality of Primary Immune Cells," Nano Letters, Vol. 6, No. 12, 2006, pp. 1522-1528. doi:10.1021/n1068003i

[10] K. J. Gilmore, S. E. Moulton and G. G Wallace, "Incorporation of Carbon Nanotubes into the Biomedical Polymer Poly(Styrene- $\beta$-Isobutylene- $\beta$-Styrene)," Carbon, Vol. 45, No. 2, 2007, pp. 402-410. doi:10.1016/j.carbon.2006.09.015

[11] M. A. Correa-Duarte, N. Wagner, J. Rojas-Chapana, C. Morsczeck, M. Thie and M. Giersig, "Fabrication and Biocompatibility of Carbon Nanotube-Based 3D Networks as Scaffolds for Cell Seeding and Growth," Nano Letters, Vol. 4, No. 11, 2004, pp. 2233-2236. doi:10.1021/n1048574f

[12] D. Cui, F. Tian, C. S. Ozkan, M. Wang and H. Gao, "Effect of Single Wall Carbon Nanotubes on Human HEK293 Cells," Toxicology Letters, Vol. 155, No. 1, 2005, pp. 73-85. doi:10.1016/j.toxlet.2004.08.015

[13] J. Chlopek, B. Czajkowska, B. Szaraniec, E. Frackowiak, K. Szostak and F. Beguin, "In Vitro Studies of Carbon Nanotubes Biocompatibility," Carbon, Vol. 44, No. 6, 2006, pp. 1106-1111. doi:10.1016/j.carbon.2005.11.022

[14] J. M. Wörle-Knirsch, K. Pulskamp and H. F. Krug, "Oops They Did It Again! Carbon Nanotubes Hoax Scientists in Viability Assays," Nano Letters, Vol. 6. No. 6, 2006, 1261-1268. doi:10.1021/n1060177c

[15] S. Fiorito, A. Serafino, F. Andreola, A. Togna and G. Togna, "Toxicity and Biocompatibility of Carbon Nanoparticles," Journal of Nanoscience and Nanotechnology, Vol. 6, No. 3, 2006, pp. 591-599. doi:10.1166/jnn.2006.125

[16] L. P. Zanello, B. Zhao, H. Hu and R. C. Haddon, "Bone Cell Proliferation on Carbon Nanotubes," Nano Letters, Vol. 6, No. 3, 2006, pp. 562-567. doi:10.1021/n1051861e

[17] Y. Ni, H. Hu, E. B. Malarkey, B. Zhao, V. Montana, R. C. Haddon and V. Parpura, "Chemically Functionalized Water Soluble Single-Walled Carbon Nanotubes Modulate Neurite Outgrowth," Journal of Nanoscience and Nanotechnology, Vol. 5, No. 10, 2005, pp. 1707-1712. doi:10.1166/jnn.2005.189

[18] M. Shim, N. W. S. Kam, R. J. Chen, Y. Li and H. Dai, "Functionalization of Carbon Nanotubes for Biocompatibility and Biomolecular Recognition," Nano Letters, Vol. 2, No. 4, 2002, pp. 285-288. doi:10.1021/n1015692j

[19] A. O. Lobo, E. F. Antunes, M. B. S. Palma, C. PachecoSoares, V. J. Trava-Airoldi and E. J. Corat, "Biocompatibility of Multi-Walled Carbon Nanotubes Grown on Titanium and Silicon Surfaces," Materials Science and Engineering $C$, Vol. 28, No. 4, 2008, pp. 532-538. doi:10.1016/j.msec.2007.04.016

[20] A. O. Lobo, E. F. Antunes, A. H. A. Machado, C. Pacheco-Soares, V. J. Trava-Airoldi and E. J. Corat, "Cell Viability and Adhesion on as Grown Multi-Wall Carbon Nanotube Films," Materials Science and Engineering C, Vol. 28, No. 2, 2008, pp. 264-269. doi:10.1016/j.msec.2007.01.003

[21] J. L. Mckenzie, M. C. Waid, R. Shi and T. J. Webster, "Decreased Functions of Astrocytes on Carbon Nanofiber Materials," Biomaterials, Vol. 25, No. 7-8, 2004, pp. 1309-1317. doi:10.1016/j.biomaterials.2003.08.006

[22] A. Magrez, S. Kasas, V. Salicio, N. Pasquier, W. S. Jin, C. Marco, S. Catsicas, B. Schwaller and L. Forro, "Cellular Toxicity of Carbon-Based Nanomaterials," Nano Letters, Vol. 6, No. 6, 2006, pp. 1121-1125. doi:10.1021/n1060162e

[23] F. Tian, D. Cui, H. Schwarz, G. G. Estrada and H. Kobayashi, "Cytotoxicity of Single-Wall Carbon Nanotubes on Human Fibroblasts," Toxicol in Vitro, Vol. 20, No. 7, 2006, pp. 1202-1212. doi:10.1016/j.tiv.2006.03.008

[24] D. W. Khang, S. Y. Kim, P. Liu-Snyder, G. T. R. Palmore, S. M. Durbin and T. J. Webster, "Enhanced Fi- 
bronectin Adsorption on Carbon Nanotube/Poly(Carbonate) Urethane: Independent Role of Surface NanoRoughness and Associated Surface Energy," Biomaterials, Vol. 28, No. 32, 2007, pp. 4756-4768.

doi:10.1016/j.biomaterials.2007.07.018

[25] R. Verdejo, G. Jell, L. Safinia, A. Bismarck, M. M. Stevens and M. S. P. Shaffer, "Reactive Polyurethane Carbon Nanotube Foams and Their Interactions with Osteoblasts," Journal of Biomedical Materials Research A, Vol. 88, No. 1, 2009, pp. 65-73. doi:10.1002/jbm.a.31698

[26] B. Y. F. Pow, A. F. T. Mak, M. S. Wong and M. Yang, "Poly(L-Lactide)/Multiwalled Carbon Nanotube Composites: Interaction with Osteoblast-Like Cells in Vitro," Advanced Materials Research, Vol. 47-50, 2008, pp. 1347-1350. doi:10.4028/www.scientific.net/AMR.47-50.1347

[27] A. R. Boccaccini, F. Chicatun, J. Cho, O. Bretcanu, J. A. Roether, S. Novak and Q. Z. Chen, "Carbon Nanotube Coatings on Bioglass-Based Tissue Engineering Scaffolds," Advanced Functional Materials, Vol. 17, No. 15, 2007, pp. 2815-2822. doi:10.1002/adfm.200600887

[28] X. Y. Liu, P. K. Chu and C. X. Ding, "Surface Modification of Titanium, Titanium Alloys, and Related Materials for Biomedical Applications," Materials Science and Engineering $R$, Vol. 47, No. 3-4, 2004, pp. 49-121. doi:10.1016/j.mser.2004.11.001

[29] S. F. Lamolle, M. Monjo, M. Rubert, H. J. Haugen, S. P. Lyngstadaas and J. E. Ellingsen, "The Effect of Hydrofluoric Acid Treatment of Titanium Surface on Nanostructural and Chemical Changes and the Growth of MC3T3-E1 Cells," Biomaterials, Vol. 30, No. 5, 2009, pp. 736-742. doi:10.1016/j.biomaterials.2008.10.052

[30] K. Cai, J. Bossert and K. D. Jandt, "Does the Nanometre Scale Topography of Titanium Influence Protein Adsorption Cand Cell Proliferation?" Colloids and Surfaces B: Biointerfaces, Vol. 49, No. 2, 2006, pp. 136-144. doi:10.1016/j.colsurfb.2006.02.016

[31] K. Cai, Y. Hu and K. D. Jandt, "Surface Engineering of Titanium Thin Films with Silk Fibroin via Layer-byLayer Technique and Its Effects on Osteoblast Growth Behavior," Journal of Biomedical Materials Research Part A, Vol. 82, No. 4, 2007, pp. 927-935. doi:10.1002/jbm.a.31233

[32] J. P. Schreckenbach and H. L. Graf, "Preparation and Characterization of Selenium Incorporated Anodic Conversion Coatings on Titanium Surfaces for Biomedical Applications," Journal of Materials Science: Materials in Medicine, Vol. 19, No. 1, 2008, pp. 233-238. doi:10.1007/s10856-006-0109-7

[33] D. C. Trimbach, B. Keller, R. Bhat, S. Zankovych, R. Pöhlmann, S. Schröter, J. Bossert and K. D. Jandt, "Enhanced Osteoblast Adhesion to Epoxide-Functionalized
Surfaces," Advanced Functional Materials, Vol. 18, No. 12, 2008, pp. 1723-1731. doi:10.1002/adfm.200701491

[34] D. L. Guillou-Buffello, R. Bareille, M. Gindre, A. Sewing, P. Laugier and J. Amédéé J, "Additive Effect of RGD Coating to Functionalized Titanium Surfaces on Human Osteoprogenitor Cell Adhesion and Spreading," Tissue Engineering Part A, Vol. 14, No. 8, 2008, pp. 1445-1455. doi:10.1089/ten.tea.2007.0292

[35] M. Dettin, A. Bagno, R. Gambaretto, G. Lucci, M. T. Conconi, N. Tuccitto, A. M. Menti, C. Grandi, C. Di Bello, A. Licciardello and G. Polzonetti, "Covalent Surface Modification of Titanium Oxide with Different Adhesive Peptides: Surface Characterization and OsteoblastLike Cell Adhesion," Journal of Biomedical Materials Research A, Vol. 90, 2008, pp. 35-45.

[36] M. Schuler, G. R. Owen, D. W. Hamilton, M. de Wild, M. Textor, D. M. Brunette and S. G. Tosatti, "Biomimetic Modification of Titanium Dental Implant Model Surfaces Using the RGDSP-Peptide Sequence: A Cell Morphology Study," Biomaterials, Vol. 27, No. 21, 2006, pp. 40034015. doi:10.1016/j.biomaterials.2006.03.009

[37] M. Morra, C. Cassinelli, G. Cascardo, L. Mazzucco, P. Borzini, M. Fini, G. Giavaresi and R. Giardino, "Collagen I-Coated Titanium Surfaces: Mesenchymal Cell Adhesion and in Vivo Evaluation in Trabecular Bone Implants," Journal of Biomedical Materials Research A, Vol. 78, No. 3, 2006, pp. 449-458. doi:10.1002/jbm.a.30783

[38] Q. Liu, J. Ding, F. K. Mante, S. L. Wunder and G. R. Baran, "The Role of Surface Functional Groups in Calcium Phosphate Nucleation on Titanium Foil: A SelfAssembled Monolayer Technique," Biomaterials, Vol. 23, No. 15, 2002, pp. 3103-3111. doi:10.1016/S0142-9612(02)00050-9

[39] A. Naofumi, Y. Atsuro, N. Yoshinobu, A. Tsukasa, U. Motohiro, S. Yoshinori, T. Kazuyuki and W. Fumio, "Carbon Nanotubes Deposited on Titanium Implant for Osteoblast Attachment," Journal of Bionanoscience, Vol. 1, No. 1, 2007, pp. 14-16. doi:10.1166/jbns.2007.003

[40] S. Sirivisoot, C. Yao, X. Xiao, B. W. Sheldon and T. J. Webster, "Greater Osteoblast Functions on Multiwalled Carbon Nanotubes Grown from Anodized Nanotubular Titanium for Orthopedic Applications," Nanotechnology, Vol. 18, No. 36, 2007, Article ID: 365102. doi:10.1088/0957-4484/18/36/365102

[41] J. Chlopek, B. Czajkowska, B. Szaraniec, E. Frackowiak, K. Szostak and F. Beguin, "In Vitro Studies of Carbon Nanotubes Biocompatibility," Carbon, Vol. 44, No. 6, 2006, pp. 1106-1111. doi:10.1016/j.carbon.2005.11.022

[42] L. Bacakova, V. Stary and P. Glogar, "Adhesion and Growth of Cells in Culture on Carbon-Carbon Composites with Different Surface Properties," Journal of Biomaterials and Tissue Engineering, Vol. 2, 1998, pp. 2-5. 